\title{
Comparison of Calving and Conception Rate after Timed Artificial Insemination (AI) with Estrus Synchronization Protocols in Crossbred Cows under Field Conditions
}

\author{
Chhavi Gupta* and R. Ramprabhu \\ Veterinary Clinical Complex, Veterinary College and Research Institute, Tirunelveli, Tamil Nadu Veterinary and Animal \\ Sciences University, Chennai, INDIA \\ "Corresponding author: C Gupta; E-mail: chhavigk@gmail.com
}

Received: 06 May, 2020

Revised: 14 July, 2020

Accepted: 19 July, 2020

\begin{abstract}
This study was performed in 48 cross bred cows to evaluate the comparative efficacy of different estrus synchronization protocols with fixed time artificial insemination. Animals were allocated into four groups i.e. Group I: ( $\mathrm{n}=12$, Two Injection Prostaglandin system) Cloprostenol Sodium $500 \mu \mathrm{gm}$ on day 0 and day 14 and AI was done 48 and 72 hours from second dose. Group II: ( $\mathrm{n}=12$, Heat-synch) day 0 Buserelin acetate $20 \mu \mathrm{gm}$, day 7 Cloprostenol sodium $500 \mu \mathrm{gm}$, on Day 8, Estradiol benzoate $(1 \mathrm{ml})$ and AI on day 10. Group III: ( $\mathrm{n}=12$, Ov-Synch) day 0 Bruserelin acetate $20 \mu \mathrm{gm}$, day 7 Cloprostenol sodium $500 \mu \mathrm{gm}$, Day 9 Buserelin acetate $20 \mu \mathrm{gm}$ and A.I. on day 10. Group IV: ( $\mathrm{n}=12$, Ov-Synch plus Indigenous progesterone sponge) on day 0 Buserelin acetate $20 \mu \mathrm{gm}$ along with insertion of progesterone sponge with $1.20 \mathrm{gm}$ natural progesterone, day 7 Cloprostenol sodium $500 \mu \mathrm{gm}$ and removal of progesterone sponge, day 9, Buserelin acetate $20 \mu \mathrm{gm}$ and AI on day 10. Inj. Buserelin acetate $20 \mu \mathrm{gm}$ was administered on day $6^{\text {th }}$ from AI in Group II, III and IV. Pregnancy was detected per rectally on day 40 after AI. In present study, estrus ratio was higher in Group II (91.66\%) followed by group IV and Group III. Conception rate was significantly higher in Group III (100\%). The calving percentage was significantly lower in group I and highest in Group III (100\%), the difference in conception and calving rate suggests the minimum embryonic losses in Group I, but no embryonic loss was recorded in Group III, IV and II.
\end{abstract}

\section{HIGHLIGHTS}

(0 Estrus synchronization protocol was developed.

(0 Estrus ratio was higher in Group II (91.66\%).

Keywords: Estrus synchronization, Fixed time AI, Ov-synch, Heat-synch, Indigenous progesterone sponge

Estrus detection and right time artificial insemination are the major limiting factors for reproductive performance in dairy farms. One management system that could potentially revolutionize reproductive management in dairy animals is the use of fixed time artificial insemination programs that eliminates the need for estrus detection (Kasimanickam et $a l ., 2005)$. It has been reported that even estrus detection rates in dairy cows are less than $50 \%$ and even rate of estrus detection is low with $\mathrm{PGF}_{2} \alpha$-induced (natural or synthetic) luteolysis.

Gonadotrophin-releasing hormone $(\mathrm{GnRH})$ and its analogues causes emergence of new follicular wave either in combination with $\mathrm{PGF}_{2} \alpha$ (Pursley et al., 1997a) or as part of a progesterone protocol (Kacar et al., 2008). Several protocols with GnRH had been compared in past like Ov-synch with double injection of $\mathrm{PGF}_{2} \alpha$ and progestin based methods (Kacar et al., 2008, Stevenson et al., 2004; Cartmill et al., 2001; Tenhagen et al., 2004),

How to cite this article: Gupta, C. and Ramprabhu, R. (2020). Comparison of calving and conception rate after timed artificial insemination (AI) with estrus synchronization protocols in crossbred cows under field conditions. J. Anim. Res., 10(4): 525-529.

Source of Support: None; Conflict of Interest: None 
Select synch, Heat synch (Pancarci et al., 2002; Bartolome et al., 2005), Pre synch (Pancarci et al., 2002) and natural breeding (Pursley et al., 1997b). Heat-synch protocol is substituting the GnRH on day 9 by Estradiol Benzoate on day 8 and fixed time A.I. on Day 10.

Progesterone based devices like Control Internal Drug Release and Progesterone Releasing Intravaginal Device, whereas Indigenous Progesterone Sponges were developed to reduce the cost of using commercially available CIDR. In India estrus synchronization using indigenous progesterone sponges (Visha et al., 2014; Devipriya et al., 2015 ) causes follicular development and ovulation.

It has been reported that by manipulating the ovarian cyclicity by controlling follicular and luteal dynamics, need of estrus detection can be eliminated by fixed time $\mathrm{AI}$ and for embryo transfer technique (Bartolome et al., 2005; Martinez et al., 2000). Ideally, a protocol has to be established in local Crossbred cows to synchronize the estrus and ovulation in both cyclic and non-cyclic animals with low embryonic mortality and high conception and calving rates.

As per Willard et al. (2003) injection GnRH on day 5 or 11 and Hansen (2002) 11 to 14 post AI increased serum Progesterone level which causes higher pregnancy rates. This treatment enhances embryo survival rates by delaying the luteolytic mechanism (Mann et al., 1995) which occurs due to failed or delayed maternal recognition of pregnancy. Some reports suggest that GnRH agonist induce ovulation to form new (or accessory) Corpus Luteum which is contradictory, GnRH induces luteinization and (or) atresia of large follicles which enhances progesterone concentration.

This study was designed with an objective of evaluating the four estrus synchronization protocols (two injection Prostaglandin system, Heat-synch, Ov-Synch and OvSynch plus Indigenous progesterone sponge) on the basis of estrus ratio, conception rate and calving rate in crossbred cows.

\section{MATERIALS AND METHODS}

The study was carried out in 48 Crossbred cows presented to Veterinary Clinical Complex, Veterinary College and Research Institute, Tirunelveli.

\section{Animals Selection}

A total 48 number of Crossbred pleuriparous cyclic and non-cyclic animals under lactation period, 40 days postpartum to 400 days postpartum were selected for this study. Per rectal examination was performed two times in twenty days interval to avoid early pregnant animal and to confirm any anatomical deformity of genitalia and mineral mixture (TANUVAS Type II) @ 50gm orally daily was supplemented. Animals were randomly distributed to different treatment groups. Estrus detection was done on the basis of history of bellowing, frequent urination, standing while animal was mounted by other animals, decrease in milk yield as per reported by the owners. Clear copious cervico vaginal discharge from vagina and on rectal examination presence of toned uterus with dominant follicle on either ovary. Pregnancy diagnosis was done on day 40 post A.I. per rectally. The treatment protocols are tabulated in table 1 .

\section{RESULTS AND DISCUSSION}

In present study, estrus activity shown by two Injection Prostaglandin system group was minimum (41.6\%) followed by Ov-synch group (66.66\%) and Ov-Synch plus CIDR Indigenous progesterone sponge $(75 \%)$. The estrus activity in Heat-synch group was significantly higher than other groups (Table 2). In this system estradiol synchronizes the ovulation of dominant follicle and distinctly increases behavioural signs of estrus. This result is in agreement with Çevik et al. (2010) and higher estrus ratio than that of Kasimanickam et al. (2005), Bartolome et al. (2005) and Pancarci et al. (2002).

Conception rate was $100 \%(12 / 12)$ in animals treated with Ov-Synch which is significantly higher than Ov-Synch plus CIDR Indigenous progesterone sponge (83.33\%) and Heat-synch $(83.33 \%)$ protocols. The conception rate with two Injection Prostaglandin system was lowest i.e. $33.33 \%$ (Table 2). Past reports suggest that two Injection Prostaglandin systems had lower conception rate than that of natural mating (Moody and Lauderdale, 1977) which is in agreement with present study. Day $0, \mathrm{GnRH}$ injection causes follicular growth in cyclic animals and non-cyclic females. The $\mathrm{PGF}_{2} \alpha$ (day 7) causes luteolysis of CL followed by decrease in serum progesterone level. The second GnRH (day 9) induces ovulation of dominant follicles which was programmed by the first $\mathrm{GnRH}$ 
Table 1: Protocols

\begin{tabular}{|c|c|c|}
\hline Groups & Number of animals & Treatment Protocol \\
\hline Group I & \multirow[t]{3}{*}{$\mathrm{n}=12$} & Day 0: Inj. Cloprostenol Sodium, $500 \mu \mathrm{gm} \mathrm{i} / \mathrm{m}$ \\
\hline Two Injection & & Day 14: Inj. Cloprostenol Sodium, $500 \mu \mathrm{gm} \mathrm{i} / \mathrm{m}$ \\
\hline Prostaglandin system & & Day 16: AI \\
\hline Group II & \multirow[t]{5}{*}{$\mathrm{n}=12$} & $\begin{array}{l}\text { Day 17: AI } \\
\text { Day 0: Inj. Buserelin Acetate, } 20 \mu \mathrm{gm} \mathrm{i/m}\end{array}$ \\
\hline \multirow[t]{4}{*}{ Heat- synch } & & Day 7: Inj.Cloprostenol Sodium, $500 \mu \mathrm{gm} \mathrm{i} / \mathrm{m}$ \\
\hline & & Day 8: Inj. Estradiol Benzoate, $1 \mathrm{ml} / \mathrm{m}$ \\
\hline & & Day 10: A.I. on early morning \\
\hline & & $\begin{array}{l}\text { Day } 6^{\text {th }} \text { Post A.I. Inj. Buserelin Acetate } 20 \mu \mathrm{gm} \mathrm{i} / \mathrm{m} \\
\text { Day } 0: \text { Inj. Buserelin Acetate } 20 \mu \mathrm{gm}, \mathrm{i} / \mathrm{m}\end{array}$ \\
\hline \multirow[t]{3}{*}{ Ov-Synch } & \multirow{3}{*}{$\mathrm{n}=\mathbf{1 2}$} & Day 7: Inj. Cloprostenol Sodium $500 \mu \mathrm{gm}, \mathrm{i} / \mathrm{m}$ \\
\hline & & Day 9: Inj. Buserelin Acetate $20 \mu \mathrm{gm} \mathrm{i} / \mathrm{m}$ \\
\hline & & Day 10: A.I. (16 hrs from second Buserelin injection) \\
\hline Group IV & $\mathrm{n}=12$ & $\begin{array}{l}\text { Day } 6^{\text {th }} \text { Post A.I. Inj. Buserelin Acetate } 20 \mu \mathrm{gm} \mathrm{i} / \mathrm{m} \\
\text { Preparation of Indigenous sponge: }\end{array}$ \\
\hline \multirow[t]{6}{*}{$\begin{array}{l}\text { Ov-Synch plus } \\
\text { Indigenous progesterone } \\
\text { sponge }\end{array}$} & & $\begin{array}{l}\text { Spongy foam } 8 \mathrm{~cm} \text { thicknesses, } 12 \mathrm{~cm} \text { diameter and tied with a cotton string of } 50 \\
\mathrm{~cm} \text { length. Sponges were sterilized by autoclaving method and were impregnated } \\
\text { with } 1.20 \mathrm{~g} \text { natural progesterone (4-Pregnene-3, 20-dione, Sigma-Aldrich) in } \\
\text { ethanolic solution. }\end{array}$ \\
\hline & & Day 0: Inj. Buserelin Acetate $20 \mu \mathrm{gm} \mathrm{i} / \mathrm{m}$ and insertion of progesterone sponge \\
\hline & & Day 7: Inj. Cloprostenol Sodium $500 \mu \mathrm{gm} \mathrm{i} / \mathrm{m}$ and removal of progesterone sponge, \\
\hline & & Day 9: Inj. Buserelin Acetate $20 \mu \mathrm{gm} \mathrm{i} / \mathrm{m}$ \\
\hline & & Day 10: A.I. \\
\hline & & Day $6^{\text {th }}$ Post A.I. Inj. Bruserelin Acetate $20 \mu \mathrm{gm} \mathrm{i} / \mathrm{m}$ \\
\hline
\end{tabular}

Table 2: Reproductive Performance Indices

\begin{tabular}{lllll}
\hline Estrus Synchronization Protocol & Total animals (n) & Estrus Ratio & Conception Rate & Calving Percentage \\
\hline Two Injection Prostaglandin system & 12 & $5 / 12(41.6)$ & $4 / 12(33.33)$ & $3 / 12(25 \%)$ \\
Heat- synch & 12 & $11 / 12(91.66 \%)$ & $10 / 12(83.33 \%)$ & $10 / 12(83.33 \%)$ \\
Ov-Synch & 12 & $8 / 12(66.66 \%)$ & $12 / 12(100 \%)$ & $12 / 12(100 \%)$ \\
Ov-synch plus CIDR Indigenous & 12 & $9 / 12(75.0 \%)$ & $10 / 12(83.33 \%)$ & $10 / 12(83.33 \%)$ \\
progesterone sponge & & & \\
\hline
\end{tabular}

injection. As per Pursley et al. (1995) the conception rate with Ov-synch was reported as 45\%. Cevik et al. (2010) reported $76.9 \%$ conception rate with $1^{\text {st }}$ AI and $100 \%$ conception rate with $2^{\text {nd }}$ A.I. But in present study the conception rate with Ov-synch was 100\% which could be due to controlled synchronization plan. In present study the conception rate with Heat-synch was $83.33 \%$ as in previous studies which was reported as $80 \%$ (Cevik et al.,
2010) in lactating dairy cows as Estradiol benzoate induces estrus, preovulatory LH surge followed by ovulation (Kacar et al., 2008; Stevenson et al., 2004; Pancarci et al., 2002). In our study the conception rate with Ov-synch plus CIDR Indigenous progesterone sponge was higher than other studies (Cevik et al., 2010; Chebel et al., 2006; Lucy et al., 2001). In this protocol Day 0, GnRH induces the emergence of follicular wave, followed by growth large 
preovulatory follicle and GnRH on Day 9 synchronizes ovulation. This protocol is effective in both cyclic and non-cyclic cattle (Kim et al., 2005).

In the present study the calving percentage was studied to access the embryonic mortality. Animals treated with Prostaglandin 4/12 (33.33\%) conceived but 3/12 (25\%) animals calved which indicates that after 40 days one conceptus was lost (Table 2). But in other all three groups conception rate and caving rate is equal which suggests that injection $\mathrm{GnRH}$ on day 6 of $\mathrm{AI}$ improves calving and conception rate. Dirandeh et al. (2014) has reported that Injection GnRH on Day 6 after AI improved reproductive performance in dairy cows under field conditions.

\section{CONCLUSION}

This study concluded that Ov-synch, Heat-synch, and Ovsynch plus CIDR Indigenous progesterone sponge showed acceptable fertility rate with estrus synchronization and fixed time AI in Crossbred cows. This protocol reduces the labour charges in estrus detection and ensures ovulation. This study also advocates the use of Inj. GnRH on Day 6 post AI can considerably reduce the early embryonic mortality. So estrus synchronization with fixed time AI and post AI GnRH therapy can considerably improves the reproductive performances of the dairy cyclic and noncyclic animals in field conditions.

\section{ACKNOWLEDGEMENTS}

The authors are thankful to the Director of Clinics, TANUVAS and Dean, Veterinary College and Research Institute, Tirunelveli to support for carry out this study successfully.

\section{REFERENCES}

Bartolome, J.A., Silvestre, F.T., Kamimura, S., Arteche, A.C.M., Melendez, P., Kelbert, D., McHale, J., Swift, K., Archbald, L.F. and Thatcher, W.W. 2005. Resynchronization of ovulation and timed insemination in lactating dairy cows I: Use of the Ovsynch and Heatsynch protocols after nonpregnancy diagnosis by ultrasonography. Theriogenology, 63: 1617-1627.

Cartmill, J.A., El-Zarkouny, S.Z., Hensley, B.A., Lamb, G.C. and Stevenson, J.S. 2001. Stage of cycle, incidence, and timing of ovulation and pregnancy rates in dairy cattle after three timed breeding protocols. J. Dairy Sci., 84: 1051-1059.
Cevik Mesut, Selcuk Murat and Dogan Soner. 2010. Comparison of Pregnancy Rates after Timed Artificial Insemination in Ovsynch, Heatsynch and CIDR-Based Synchronization Protocol in Dairy Cows. Kafkas Univ. Vet. Fak. Derg., 16(1): 85-89.

Chebel, R.C., Santos, J.E.P., Cerri, R.L.A, Rutigliano, H.M. and Bruno, R.G.S. 2006. Reproduction in dairy cows following progesterone inserts presychronizaion and resynchronization protocols. J. Dairy Sci., 89: 4205-4219.

Devipriya, K., Eswari, S. and Nanjappan, K. 2015. Induction of estrus and fertility response in true anoestrus buffaloes using intravaginal progesterone sponge during summer. J. Anim. Res., 5(2): 389-391.

Dirandeh, E., Rezaei Roodbari, A. and Shohreh, B. 2014. Effect of GnRH injection at day 6 and 12 after insemination on fertility of Holstein dairy cows during the warm season. Int. J. Adv. Biol. Biomed. Res., 2(1): 125-131.

Hansen, P.J. 2002. Embryonic mortality in cattle from the embryo's perspective. J. Anim. Sci., 80: 33-44.

Kacar, C., Kamiloglu, N.N., Ucar, O., Ar, U.C., Pancarc, S.M. and Gungor, O. 2008. Effect of Ovsynch and Cosynch synchronization programmes combined with beta-carotene + vitamin $\mathrm{E}$ administration upon the pregnancy rates in cows. Kafkas Univ. Vet. Fak. Derg., 14(1): 45-50.

Kasimanickam, R., Cornwell, J.M. and Nebel, R.L. 2005. Fertility following fixed-time AI or insemination at observed estrus in Ovsynch and Heatsynch programs in lactating dairy cows. Theriogenology, 63: 2550-2559.

Kim, U.H., Suh, G.H., Nam, H.W., Kang, H.G. and Kim, I.H. 2005. Follicular wave emergence, luteal function and synchrony of ovulation following GnRH or estradiol benzoate in a CIDR-treated, lactating Holstein cows. Theriogenology, 63: $260-268$

Lucy, M.C., Billings, H.J., Butler, W.R., Ehniss, L.R., Fields, M.J., Kesler, D.J., Kinder, J.E., Mattos, R.C., Short, R.E., Thatcher, W.W., Wettemann, R.P., Yelich, J.V.and Hafs, H.D. 2001. Efficacy of an intravaginal progesterone insert and an injection of PGF2 $\alpha$ for synchronizing estrus and shortening the interval to pregnancy in postpartum beef cows, peripubertal beef heifers, and dairy heifers. J. Anim. Sci., 79: 982-995.

Mann, G.E., Lamming, G.E. and Fray, M.D. 1995. Plasma oestradiol and progesterone during early pregnancy in the cow and the effects of treatment with Buserelin. Anim. Reprod. Sci., 37:121-131.

Martinez, M.F., Adams, G.P., Kastelic, J.P., Bergfelt, D.R.and Mapletoft, R.J. 2000. Induction of follicular wave emergence for estrus synchronization and artificial insemination in heifers. Theriogenology, 54: 757-769. 
Moody, E.L. and Lauderdale J.W. 1977. Fertility of cattle following PGF2 $\alpha . I n$ : American Society of Animal Science. $69^{\text {th }}$ Annual Meeting.(Abstr.). pp. 189

Pancarci, S.M., Jordan, E.R., Risco, C.A., Schouten, M.J., Lopes, F.L., Moreira, F. and Thatcher, W.W. 2002. Use of estradiol cypionate in a presynchronized timed artificial insemination program for lactating dairy cattle. J. Dairy Sci., 85: 122-131.

Pursley, J.R., Silcox, R.W. and Wiltbank, M.C. 1995. Conception rates at differing intervals between AI and ovulation. J. Dairy. Sci., 78 (Suppl. 1): 279.

Pursley, J.R, Kosorok, M.R. and Wiltbank, M.C. 1997b. Reproductive management of lactating dairy cows using synchronization of ovulation. J. Dairy Sci., 80: 301-306.

Pursley, J.R., Wiltbank, M.C., Stevenson, J.S., Ottobre, J.S., Garverick, H.A. and Anderson, L.L. 1997a. Pregnancy rates per artificial insemination for cows and heifers inseminated at a synchronized ovulation or synchronized estrus. J. Dairy Sci., 80: 295-300.
Stevenson, J.S., Tiffany, S.M. and Lucy, M.C. 2004. Use of estradiol cypionate as a substitute for GnRH in Protocols for synchronizing ovulation in dairy cattle. J. Dairy Sci., 87: 3298-3305.

Tenhagen, B.A., Surholt, R., Wittke, M., Vogel, C., Drillich, M. and Heuwieser, W. 2004. Use of Ovsynch in dairy herds differences between primiparous and multiparous cows. Anim. Reprod. Sci., 81: 1-11.

Visha, P., Jayachandran, S., Nanjappan, K. and Palanisammi, A. 2014. Follicular growth pattern in buffaloes synchronized to estrus with progesterone impregnated intravaginal songes. Int. J. Environ. Sci. TE., 3(3): 960-965.

Willard, S., Gandy, S., Bowers, S., Graves, K., Elias, A. and Whisnant, C. 2003. The effects of GnRH administration post insemination on serum concentrations of progesterone and pregnancy rates in dairy cattle exposed to mild summer heat stress. Theriogenology, 59: 1799-1810. 
